\title{
Effect of Intermolecular Hydrogen Bonding on Low-Surface-Energy Material of Poly(vinylphenol)
}

\author{
Han-Ching Lin, ${ }^{\dagger}$ Chih-Feng Wang, ${ }^{\dagger}$ Shiao-Wei Kuo ${ }^{\dagger}{ }^{\text {Pao-Hsiang Tung, }}{ }^{\dagger}$ Chih-Feng Huang,${ }^{\dagger}$ \\ Chun-Hung Lin, ${ }^{\S}$ and Feng-Chih Chang*, $\dagger$ \\ Institute of Applied Chemistry, National Chiao Tung University, 30050 Hsinchu, Department of Materials \\ Science and Engineering, I-Shou University, 84041 Kaohsiung, and National Nano Device Laboratories, \\ 30050 Hsinchu, Taiwan
}

Received: November 29, 2006; In Final Form: February 13, 2007

\begin{abstract}
We discovered that poly(vinylphenol) $(\mathrm{PVPh})$ possesses an extremely low surface energy $\left(15.7 \mathrm{~mJ} / \mathrm{m}^{2}\right)$ after a simple thermal treatment procedure, even lower than that of poly(tetrafluoroethylene) $\left(22.0 \mathrm{~mJ} / \mathrm{m}^{2}\right)$ calculated on the basis of the two-liquid geometric method. Infrared analyses indicate that the intermolecular hydrogen bonding of PVPh decreases by converting the hydroxyl group into a free hydroxyl and increasing intramolecular hydrogen bonding after thermal treatment. PVPh results in a lower surface energy because of the decrease of intermolecular hydrogen bonding between hydroxyl groups. In addition, we also compared surface energies of PVPh-co-PS (polystyrene) copolymers (random and block) and their corresponding blends. Again, these random copolymers possess a lower fraction of intermolecular hydrogen bonding and surface energy than the corresponding block copolymers or blends after similar thermal treatment. This finding provides a unique and easy method to prepare a low-surface-energy material through a simple thermal treatment procedure without using fluoro polymers or silicones.
\end{abstract}

\section{Introduction}

The performance of polymeric materials is often dictated by surface properties, such as wettability, friction, and adhesion. In particular, hydrophobicity and oleophobicity have attracted tremendous interest due to their wide range of applications. ${ }^{1-4}$ Both poly(dimethylsiloxane) (PDMS) and poly(tetrafluoroethylene) (PTFE) are two well-known examples possessing low surface energies. ${ }^{5-8}$ PTFE may be regarded as the benchmark lower surface energy material, displaying water repellency ${ }^{9}$ in combination with other desirable properties. ${ }^{10}$ The small size of the fluorine atom with high electronegativity, low polarizability, and strong fluorine-fluorine repulsion ${ }^{11}$ results in weak intermolecular forces of fluorinated polymer chains and thus relatively lower surface energies. However, PTFE and many fluorinated polymers have some application limitations such as high cost and poor processibility. Many efforts have been attempted to search for low-surface-free-energy polymeric materials with low cost, easy processibility, and good filmforming characteristics. ${ }^{12-14}$

The amorphous comblike polymers possessing a flexible linear backbone on the side chain with low intermolecular interaction generally exhibit a low surface energy. ${ }^{15}$ We have found that the intermolecular hydrogen bonding between the hydroxyl groups increases their surface energies in the polybenzoxazine system. ${ }^{12}$ Chung et al. ${ }^{16}$ have reported that the presence of amide groups in the main-chain-fluorinated liquidcrystalline polymer system tends to induce strong intermolecular hydrogen bonding and results in a higher surface energy and hydrophilicity. The nature of the pendent chain has a most

* To whom correspondence should be addressed. E-mail: changfc@ mail.nctu.edu.tw. Phone/fax: 886-3-5131512.

$\dagger$ National Chiao Tung University.

$\doteqdot$ I-Shou University.

$\S$ National Nano Device Laboratories. profound effect in determining the surface energy of the material; therefore, a low-surface-free-energy material can be obtained by decreasing the intermolecular interaction from the comblike polymer with a flexible linear backbone. ${ }^{17}$ In this study, the relationships between the hydrogen-bonding strength and the surface energy of poly(vinylphenol) (PVPh) before and after thermal treatment were investigated on the basis of infrared spectroscopy and contact angle measurements. It is well-known that high-temperature thermal treatment tends to disrupt hydrogen bonds and the hydrogen bonds are re-formed in a different distribution (inter- and intramolecular) after fast cooling to ambient temperature relative to that before thermal annealing. Besides, the free hydroxyl content is also changed. To our surprise, we discovered that $\mathrm{PVPh}$, a fluorine- and siliconefree polymer, can possess an extremely low surface energy (15.7 $\mathrm{mJ} / \mathrm{m}^{2}$ ) after a simple thermal treatment procedure which is even lower than that of PTFE $\left(22.0 \mathrm{~mJ} / \mathrm{m}^{2}\right)$ calculated on the basis of the two-liquid geometric method. To the best of our knowledge, this is the first reported thermoplastic to achieve a low surface energy by weakening the intermolecular hydrogenbonding interaction. Furthermore, we use PVPh/PS (polystyrene) random and block copolymers and their respective blends to investigate the importance of the hydrogen-bonding strength in the resulting surface energy.

\section{Experimental Part}

Preparation of PVPh/PS Random and Block Copolymers and Blends. The detailed synthesis procedures of PVPh- $r$-PS and PVPh- $b$-PS copolymers have been reported previously. ${ }^{18,19}$ Table 1 lists the characterizations of $\mathrm{PVPh}, \mathrm{PS}$, and $\mathrm{PVPh} / \mathrm{PS}$ random and block copolymers. Various binary PVPh/PS blend compositions were prepared by solution-casting. A THF solution containing $5 \mathrm{wt} \%$ polymer was stirred for $6-8 \mathrm{~h}$ and then cast onto a Teflon dish. The solution was left to evaporate at room 
TABLE 1: Formulations and Thermal Properties of PVPh-co-PS Copolymers and Corresponding Blends

\begin{tabular}{|c|c|c|c|c|c|}
\hline copolymer & $\begin{array}{c}\text { phenol ratio }^{a} \\
(\mathrm{~mol} \mathrm{\%})\end{array}$ & $M_{\mathrm{n}}{ }^{b}$ & $M_{\mathrm{w}} / M_{\mathrm{n}}^{b}$ & $\begin{array}{c}T_{\mathrm{g}} \\
\left({ }^{\circ} \mathrm{C}\right)\end{array}$ & $\begin{array}{c}T_{\mathrm{d}} \\
\left({ }^{\circ} \mathrm{C}\right)\end{array}$ \\
\hline PS & 0 & 11000 & 1.21 & 100 & 371 \\
\hline PVPh22-r-PS78 & 21.5 & 24000 & 2.05 & 104 & 36 \\
\hline PVPh36-r-PS64 & 36.0 & 17400 & 2.05 & 118 & 36 \\
\hline PVPh55-r-PS45 & 55.2 & 23200 & 2.10 & 154 & 35 \\
\hline PVPh78-r-PS22 & 77.8 & 24400 & 2.34 & 162 & 353 \\
\hline PVPh24-b-PS76 & 24.2 & 12400 & 1.13 & 101,172 & 370 \\
\hline PVPh49- $b$-PS51 & 49.0 & 17400 & 1.09 & 98,175 & 36 \\
\hline PVPh71-b-PS29 & 71.0 & 30200 & 1.08 & 99,177 & 35 \\
\hline $\mathrm{PVPh} 80-b$-PS20 & 80.7 & 20900 & 1.13 & 99,176 & 35 \\
\hline $\mathrm{PVPh} / \mathrm{PS}=20 / 80$ & 20.0 & & & 98,178 & 36 \\
\hline $\mathrm{PVPh} / \mathrm{PS}=60 / 40$ & 60.0 & & & 101,180 & 36 \\
\hline $\mathrm{PVPh} / \mathrm{PS}=80 / 20$ & 80.0 & & & 99,182 & 35 \\
\hline $\mathrm{PVPh}$ & 100 & 20000 & 1.07 & 175 & 352 \\
\hline
\end{tabular}

temperature for 1 day and dried in vacuum at room temperature for 2 days. The thermal treatment was carried out by placing the as-prepared polymer film in a vacuum oven at 120 or $180{ }^{\circ} \mathrm{C}$ for $24 \mathrm{~h}$ and then quenching to ambient temperature.

Characterizations. ${ }^{1} \mathrm{H}$ NMR spectra were recorded on a Varian Unity Inova 500 FT NMR spectrometer operated at 500 $\mathrm{MHz}$; deuterated chloroform was used as the solvent. Thermal analyses were performed using a DuPont DSC-9000 differential scanning calorimeter operated at a scan rate of $20^{\circ} \mathrm{C} / \mathrm{min}$ within a temperature range from 30 to $220^{\circ} \mathrm{C}$. Thermal stabilities of the cured samples were investigated using a DuPont 2050 TGA instrument operated at a rate of $10{ }^{\circ} \mathrm{C} / \mathrm{min}$ from 30 to $700{ }^{\circ} \mathrm{C}$ under a nitrogen flow. Infrared spectroscopic measurements were conducted on a Nicolet Avatar 320 FTIR spectrophotometer; 32 scans were collected with a spectral resolution of 1 $\mathrm{cm}^{-1}$. All sample preparations were under continuous nitrogen flow to ensure minimal sample oxidation or degradation. Surface roughness profiles of film structures were acquired using a Digital Instruments DI5000 scanning probe microscope in the tapping mode. The values of root-mean-square (rms) roughness were calculated over scan areas of $5 \mu \mathrm{m} \times 5 \mu \mathrm{m}$. For contact angle measurements, deionized water and diiodomethane (DIM) were chosen as testing liquids because significant amounts of data are available for these liquids. The advancing contact angle measurement of a polymer sample was determined at $25^{\circ} \mathrm{C}$ after injection of a liquid drop $(5 \mu \mathrm{L})$ onto the surface, and a Krüss GH-100 goniometer interfaced to image-capture software was employed to perform the measurement. A two-liquid geometric method was employed to determine the surface energy. ${ }^{20}$ XPS was performed using a VG Microlab $310 \mathrm{~F}$ spectrometer equipped with an $\mathrm{Al} \mathrm{K} \alpha \mathrm{X}$-ray source $(1486.6 \mathrm{eV})$.

\section{Results and Discussion}

Formulations and thermal properties of these synthesized copolymers are summarized in Table 1 . It is well-known that a high temperature above $T_{\mathrm{g}}$ tends to partially disrupt hydrogen bond formation, and this is why we chose $180{ }^{\circ} \mathrm{C}$ as the thermal treatment temperature. Thermal treatment at $120^{\circ} \mathrm{C}$ was chosen because it is between the $T_{\mathrm{g}}$ values of PS and PVPh. Furthermore, 120 and $180{ }^{\circ} \mathrm{C}$ are both far lower than the decomposition temperature (Table 1), and the thermal treatment should not damage the polymer structure. Table 2 lists the surface roughness, advancing contact angles, and surface free energies of all specimens, before and after thermal treatment. The surface roughnesses of all specimens are lower than $20 \mathrm{~nm}$; therefore, the influence of topography on the surface free energy is

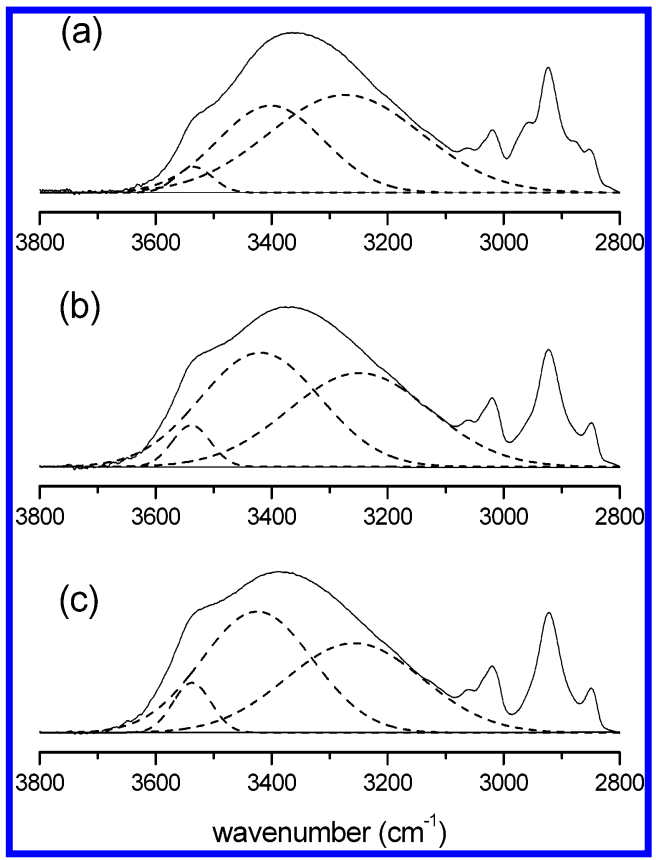

Figure 1. FTIR spectra and curve-fitting result of pure $\mathrm{PVPh}$ (a) at room temperature and after (b) $120^{\circ} \mathrm{C}$ and (c) $180^{\circ} \mathrm{C}$ thermal treatment procedures.

negligible. The advancing contact angle is relatively less sensitive to surface roughness and heterogeneity than the receding angle; thus, the advancing contact angle data are commonly used to calculate the components of surface and interfacial tension. ${ }^{21,22}$ In the pure PVPh system, the advancing contact angles of water and diiodomethane increase substantially after thermal treatment, resulting in a significant decrease in surface free energy (from 41.8 to $15.7 \mathrm{~mJ} / \mathrm{m}^{2}$ ). Compared with the surface free energy of PTFE $\left(22.0 \mathrm{~mJ} / \mathrm{m}^{2}\right)$ by using the same testing liquids and calculated method, ${ }^{23}$ surprisingly, the surface free energy of this fluorine- and silicone-free PVPh $(15.7 \mathrm{~mJ} /$ $\mathrm{m}^{2}$ ) is significantly lower than that of the pure PTFE after the simple thermal treatment procedure.

It has been reported that increasing the intermolecular hydrogen bonding of a polymeric material tends to increase its surface energy. ${ }^{12,16} \mathrm{We}$ speculate that the decrease of surface energy in the present case is due to the decrease of the intermolecular hydrogen-bonding interaction. Figure 1 shows the FTIR spectra and the curve-fitting result of the pure PVPh at room temperature and after 120 and $180{ }^{\circ} \mathrm{C}$ thermal treatment for 1 day. For clarity, the spectra only display the hydroxyl stretching region between 2800 and $3800 \mathrm{~cm}^{-1}$. According to a recent study, ${ }^{24}$ the $-\mathrm{OH}$ band can be fitted by three Gaussian functions: a narrower shoulder band at $3525 \mathrm{~cm}^{-1}$ represents the free hydroxyl group, the peak at $v \doteqdot 3280 \mathrm{~cm}^{-1}$ corresponds to the hydroxyl groups involved in intermolecular hydrogen bonding, and the peak at $v \doteqdot 3420 \mathrm{~cm}^{-1}$ corresponds to the hydroxyl groups involved in intramolecular hydrogen bonding. Scheme 1 displays the schematic representation of free hydroxyl and inter- and intramolecular hydrogen bonding in poly(vinylphenol). During the process of fast cooling, it is more favorable to re-form hydrogen bonds from neighboring hydroxyl groups or those in the vicinity (most likely from the same chain, defined as an intramolecular hydrogen bond). This is probably the reason for the decrease in the number of intermolecular hydrogen bond (longer distance between hydroxyls, mostly from different chains) content. Table 3 lists results of curve-fitting data for PVPh before and after the thermal treatment. Combining our analyses of the FTIR spectra and the corresponding curve- 
TABLE 2: Root-Mean-Square Surface Roughness, Advancing Contact Angle for Water and Diiodomethane, Surface Free Energy, and XPS Analysis of PVPh/PS Copolymers (Standard Deviations in the Range 0.3-2.4)

\begin{tabular}{|c|c|c|c|c|c|c|c|c|c|c|}
\hline \multirow[b]{3}{*}{ polymer } & \multicolumn{4}{|c|}{ before $180^{\circ} \mathrm{C}$ thermal treatment } & \multicolumn{6}{|c|}{ after $180^{\circ} \mathrm{C}$ thermal treatment } \\
\hline & \multirow[b]{2}{*}{$\begin{array}{c}\text { roughness } \\
(\mathrm{nm})\end{array}$} & \multicolumn{2}{|c|}{ contact angle (deg) } & \multirow[b]{2}{*}{$\begin{array}{c}\gamma \\
\left(\mathrm{mJ} / \mathrm{m}^{2}\right)\end{array}$} & \multirow[b]{2}{*}{$\begin{array}{l}\text { roughness } \\
\quad(\mathrm{nm})\end{array}$} & \multicolumn{2}{|c|}{ contact angle (deg) } & \multirow[b]{2}{*}{$\begin{array}{c}\gamma \\
\left(\mathrm{mJ} / \mathrm{m}^{2}\right)\end{array}$} & \multicolumn{2}{|c|}{ XPS: oxygen content ( $\mathrm{mol} \%)$} \\
\hline & & $\mathrm{H}_{2} \mathrm{O}$ & DIM & & & $\mathrm{H}_{2} \mathrm{O}$ & DIM & & $\begin{array}{c}\text { before } \\
\text { thermal } \\
\text { treatment }\end{array}$ & $\begin{array}{c}\text { after } \\
\text { thermal } \\
\text { treatment }\end{array}$ \\
\hline PVPh & 7.8 & 70.5 & 42.1 & 41.8 & 5.1 & 105.5 & 84.1 & 15.7 & 13.5 & 17.3 \\
\hline PVPh22-r-PS78 & 8.2 & 100.0 & 53.1 & 33.1 & 3.8 & 105.5 & 75.6 & 19.8 & & \\
\hline PVPh36- $r$-PS64 & 4.3 & 101.5 & 56.4 & 31.2 & 5.4 & 107.3 & 75.2 & 20.1 & & \\
\hline PVPh55-r-PS45 & 7.1 & 97.7 & 53.6 & 32.5 & 4.7 & 105.8 & 76.3 & 19.4 & & \\
\hline PVPh78-r-PS22 & 5.6 & 88.9 & 49.1 & 34.8 & 5.2 & 108.5 & 79.8 & 17.4 & 12.4 & 16.9 \\
\hline PVPh24- $b$-PS76 & 6.3 & 92.0 & 44.2 & 37.5 & 7.2 & 105.7 & 43.6 & 41.0 & & \\
\hline PVPh49-b-PS51 & 4.7 & 102.5 & 47.9 & 37.0 & 3.6 & 103.9 & 42.6 & 41.0 & & \\
\hline PVPh71- $b$-PS29 & 8.4 & 95.4 & 43.9 & 38.1 & 6.4 & 103.3 & 59.5 & 29.4 & & \\
\hline PVPh80- $b$-PS20 & 5.9 & 100.6 & 47.8 & 36.6 & 5.8 & 103.5 & 75.6 & 19.8 & 10.4 & 14.9 \\
\hline $\mathrm{PVPh} / \mathrm{PS}=20 / 80$ & 14.2 & 100.4 & 44.0 & 40.1 & 11.3 & 101.2 & 41.2 & 41.1 & & \\
\hline $\mathrm{PVPh} / \mathrm{PS}=40 / 60$ & 17.6 & 98.6 & 42.1 & 40.8 & 9.7 & 101.8 & 43.5 & 40.8 & & \\
\hline $\mathrm{PVPh} / \mathrm{PS}=60 / 40$ & 19.8 & 90.1 & 41.0 & 40.2 & 14.6 & 100.5 & 44.7 & 40.2 & & \\
\hline $\mathrm{PVPh} / \mathrm{PS}=80 / 20$ & 13.7 & 76.7 & 43.3 & 40.4 & 10.5 & 100.9 & 52.6 & 33.6 & 12.5 & 12.0 \\
\hline PS & 3.2 & 100.6 & 41.3 & 40.9 & & & & & & \\
\hline
\end{tabular}

SCHEME 1: Schematic Representation of Inter- and Intramolecular Hydrogen Bonding and Free Hydroxyl in Poly(vinylphenol)

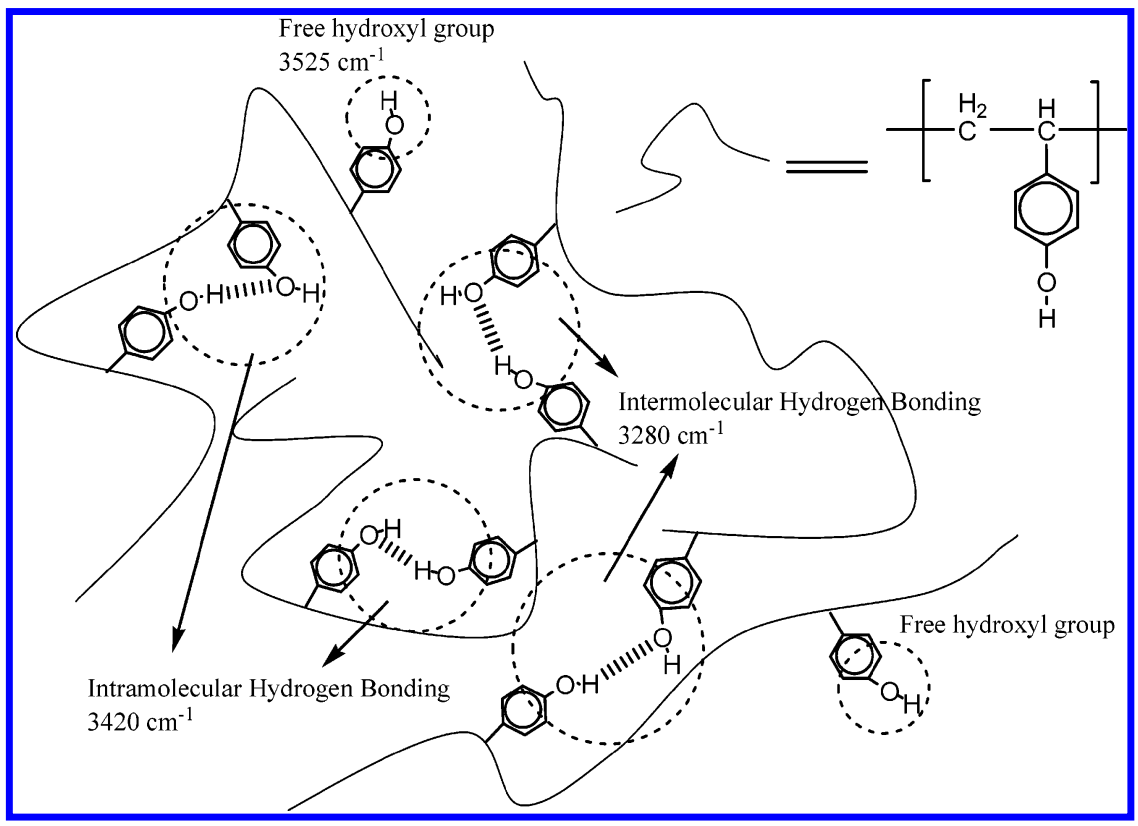

TABLE 3: Results of Curve-Fitting the Data for PVPh, PVPh-co-PS, and PVPh/PS Blends before and after the Thermal Treatment

\begin{tabular}{|c|c|c|c|c|c|c|c|c|c|c|c|c|}
\hline \multirow[b]{3}{*}{ polymer } & \multicolumn{6}{|c|}{ before $180{ }^{\circ} \mathrm{C}$ thermal treatment } & \multicolumn{6}{|c|}{ after $180^{\circ} \mathrm{C}$ thermal treatment } \\
\hline & \multicolumn{2}{|c|}{ intermolecular $\mathrm{O}-\mathrm{H}$} & \multicolumn{2}{|c|}{ intramolecular $\mathrm{O}-\mathrm{H}$} & \multicolumn{2}{|c|}{ free $\mathrm{O}-\mathrm{H}$} & \multicolumn{2}{|c|}{ intermolecular $\mathrm{O}-\mathrm{H}$} & \multicolumn{2}{|c|}{ intramolecular $\mathrm{O}-\mathrm{H}$} & \multicolumn{2}{|c|}{ free $\mathrm{O}-\mathrm{H}$} \\
\hline & $\begin{array}{c}v \\
\left(\mathrm{~cm}^{-1}\right)\end{array}$ & $\begin{array}{l}A_{\mathrm{b}} \\
(\%)\end{array}$ & $\begin{array}{c}v \\
\left(\mathrm{~cm}^{-1}\right)\end{array}$ & $\begin{array}{c}A_{\mathrm{b}} \\
(\%)\end{array}$ & $\begin{array}{c}v \\
\left(\mathrm{~cm}^{-1}\right)\end{array}$ & $\begin{array}{c}A_{\mathrm{b}} \\
(\%)\end{array}$ & $\begin{array}{c}v \\
\left(\mathrm{~cm}^{-1}\right)\end{array}$ & $\begin{array}{l}A_{\mathrm{b}} \\
(\%)\end{array}$ & $\begin{array}{c}v \\
\left(\mathrm{~cm}^{-1}\right)\end{array}$ & $\begin{array}{l}A_{\mathrm{b}} \\
(\%)\end{array}$ & $\begin{array}{c}v \\
\left(\mathrm{~cm}^{-1}\right)\end{array}$ & $\begin{array}{l}A_{\mathrm{b}} \\
(\%)\end{array}$ \\
\hline $\mathrm{PVPh}$ & 3276 & 62 & 3400 & 35 & 3534 & 3 & 3279 & 48 & 3421 & 44 & 3538 & 8 \\
\hline PVPh22-r-PS78 & 3289 & 53 & 3422 & 36 & 3546 & 11 & 3308 & 30 & 3445 & 49 & 3547 & 21 \\
\hline PVPh36- $r$-PS64 & 3280 & 55 & 3414 & 39 & 3545 & 6 & 3303 & 37 & 3442 & 47 & 3545 & 16 \\
\hline PVPh55-r-PS45 & 3279 & 56 & 3409 & 39 & 3541 & 5 & 3290 & 41 & 3438 & 46 & 3542 & 13 \\
\hline PVPh78-r-PS22 & 3278 & 56 & 3404 & 39 & 3541 & 5 & 3282 & 46 & 3433 & 45 & 3538 & 9 \\
\hline PVPh24- $b$-PS76 & 3280 & 59 & 3412 & 35 & 3435 & 6 & 3285 & 55 & 3415 & 35 & 3536 & 10 \\
\hline PVPh71- $b$-PS29 & 3280 & 58 & 3416 & 37 & 3536 & 5 & 3284 & 50 & 3416 & 41 & 3535 & 9 \\
\hline $\mathrm{PVPh} 80-b$-PS20 & 3285 & 57 & 3418 & 38 & 3539 & 5 & 3285 & 49 & 3417 & 43 & 3535 & 8 \\
\hline $\mathrm{PVPh} / \mathrm{PS}=20 / 80$ & 3282 & 58 & 3413 & 36 & 3534 & 6 & 3285 & 56 & 3416 & 34 & 3437 & 10 \\
\hline $\mathrm{PVPh} / \mathrm{PS}=60 / 40$ & 3283 & 59 & 3415 & 36 & 3535 & 5 & 3286 & 55 & 3418 & 37 & 3435 & 8 \\
\hline $\mathrm{PVPh} / \mathrm{PS}=80 / 20$ & 3281 & 59 & 3416 & 37 & 3536 & 4 & 3285 & 52 & 3419 & 40 & 3434 & 8 \\
\hline
\end{tabular}

fitting results (Figure 1 and Table 3) and the variations in the surface energies (Table 2), it is clear that decreasing the fraction of intermolecular hydrogen bonding leads to a decrease in the surface free energy. This observation is in good agreement with the result of our previous study on the surface-free-energy effect. $^{12}$ 

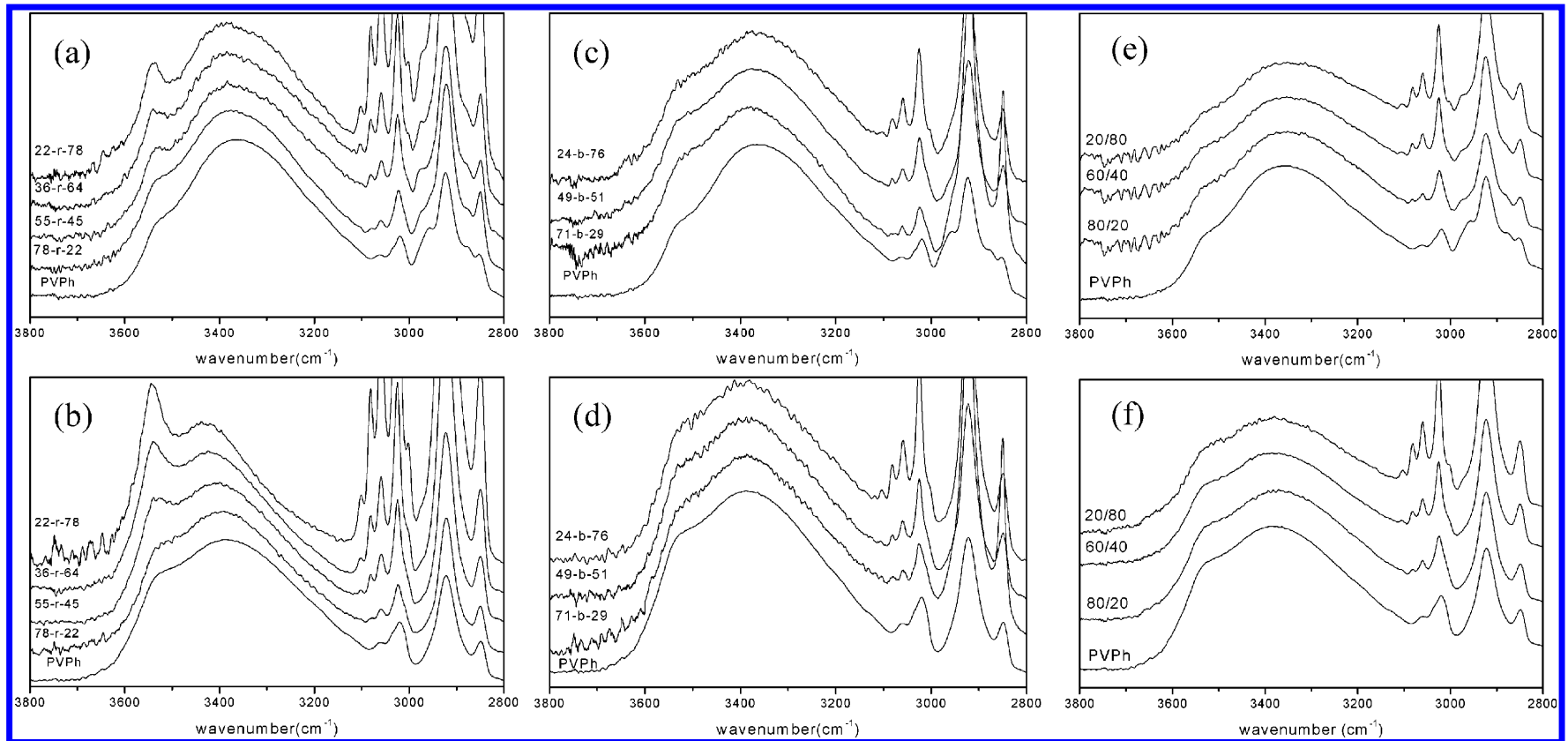

Figure 2. FTIR spectra of PVPh/PS random and block copolymers and blends (a, c, e) before and (b, $d, f)$ after the thermal treatment.

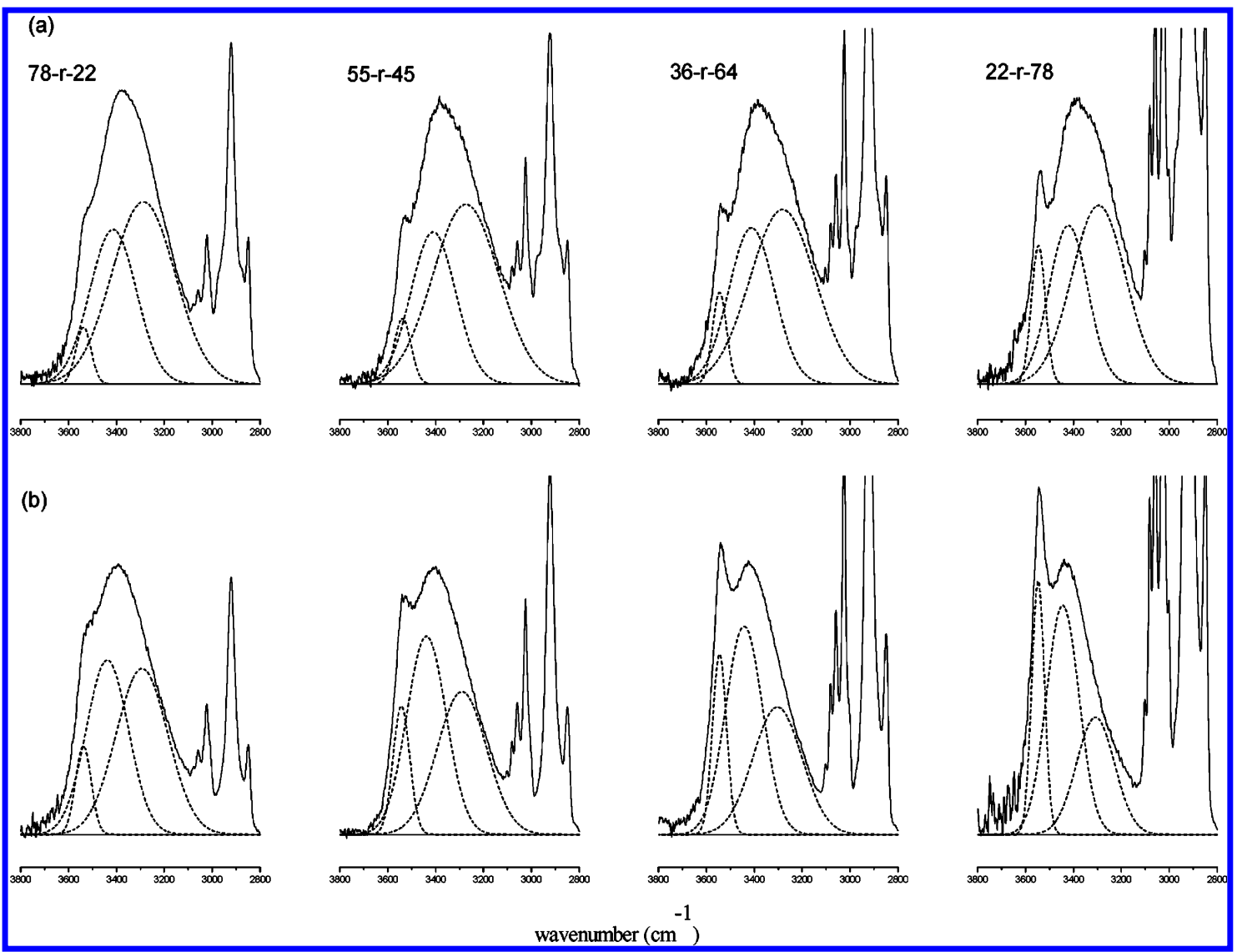

Figure 3. FTIR spectra and curve-fitting result of PVPh- $r$-PS copolymers (a) at room temperature and (b) after the $180{ }^{\circ} \mathrm{C}$ thermal treatment procedure.

To further investigate the importance of decreasing the fraction of intermolecular hydrogen bonding or increasing the fraction of free hydroxyl groups in lowering the surface free energy, a series of PVPh/PS random and block copolymers and their corresponding blends were prepared. Their surface energies were measured through the same method as that for the pure $\mathrm{PVPh}$, and the results are summarized in Table 2. Clearly, the contact angles and resulting $\gamma$ of $\mathrm{PVPh} / \mathrm{PS}$ blends show no significant change before or after $180{ }^{\circ} \mathrm{C}$ thermal treatment. The
PVPh- $r$-PS copolymers possess the most drastic reduction in surface energy after the thermal treatment in comparison with corresponding block copolymers and blends under comparable compositions. Figure 2 summarizes FTIR data at the hydroxyl stretching region of $\mathrm{PVPh} / \mathrm{PS}$ random and block copolymers and blends before and after $180{ }^{\circ} \mathrm{C}$ thermal treatment for 1 day. Figures 3-5 display their respective FTIR spectra and curvefitting results before and after the thermal treatment. Table 3 also lists results of curve-fitting data for $\mathrm{PVPh}-$ co-PS and $\mathrm{PVPh} /$ 
3408 J. Phys. Chem. B, Vol. 111, No. 13, 2007

Lin et al.

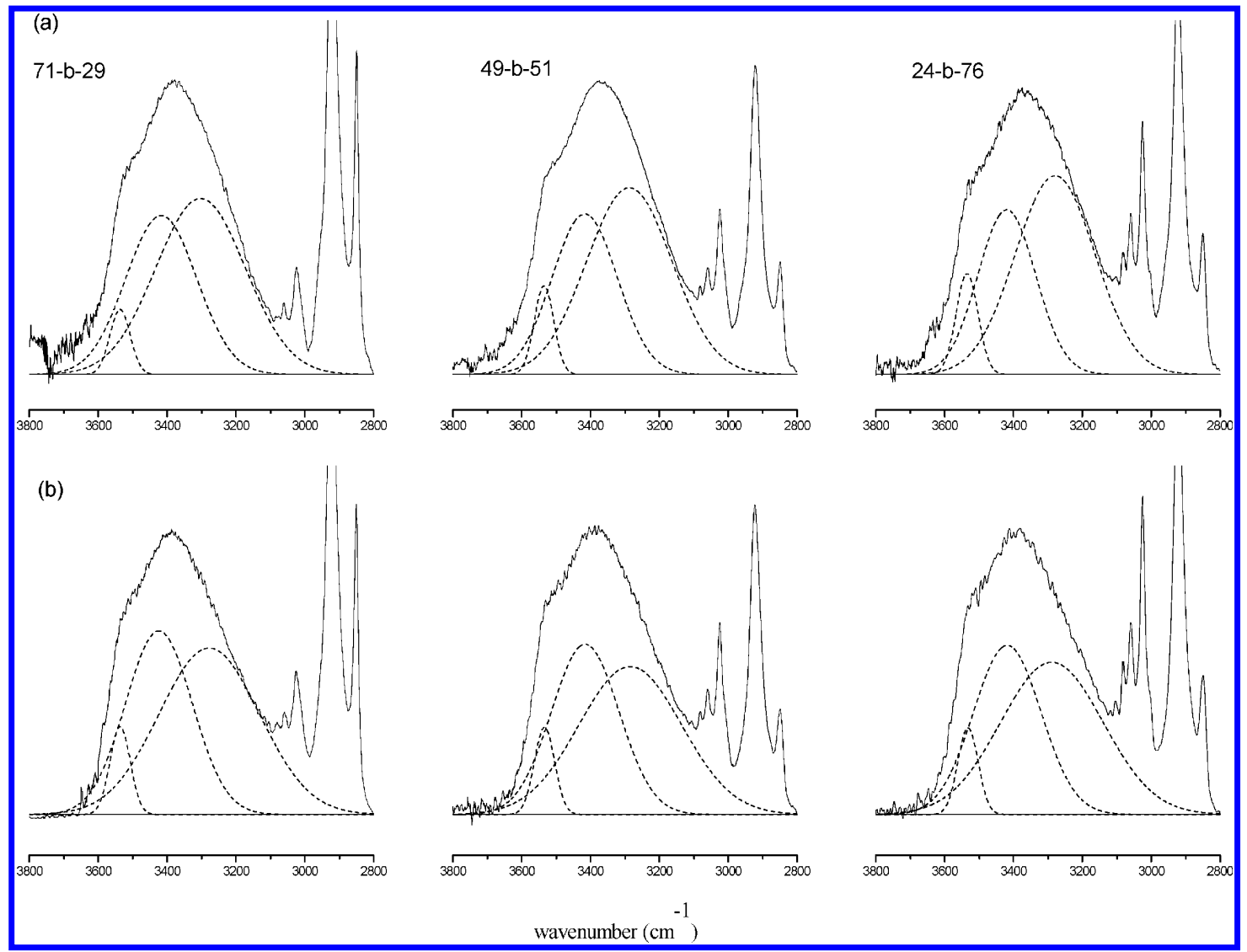

Figure 4. FTIR spectra and curve-fitting result of PVPh- $b$-PS copolymers (a) at room temperature and (b) after the $180{ }^{\circ} \mathrm{C}$ thermal treatment procedure.

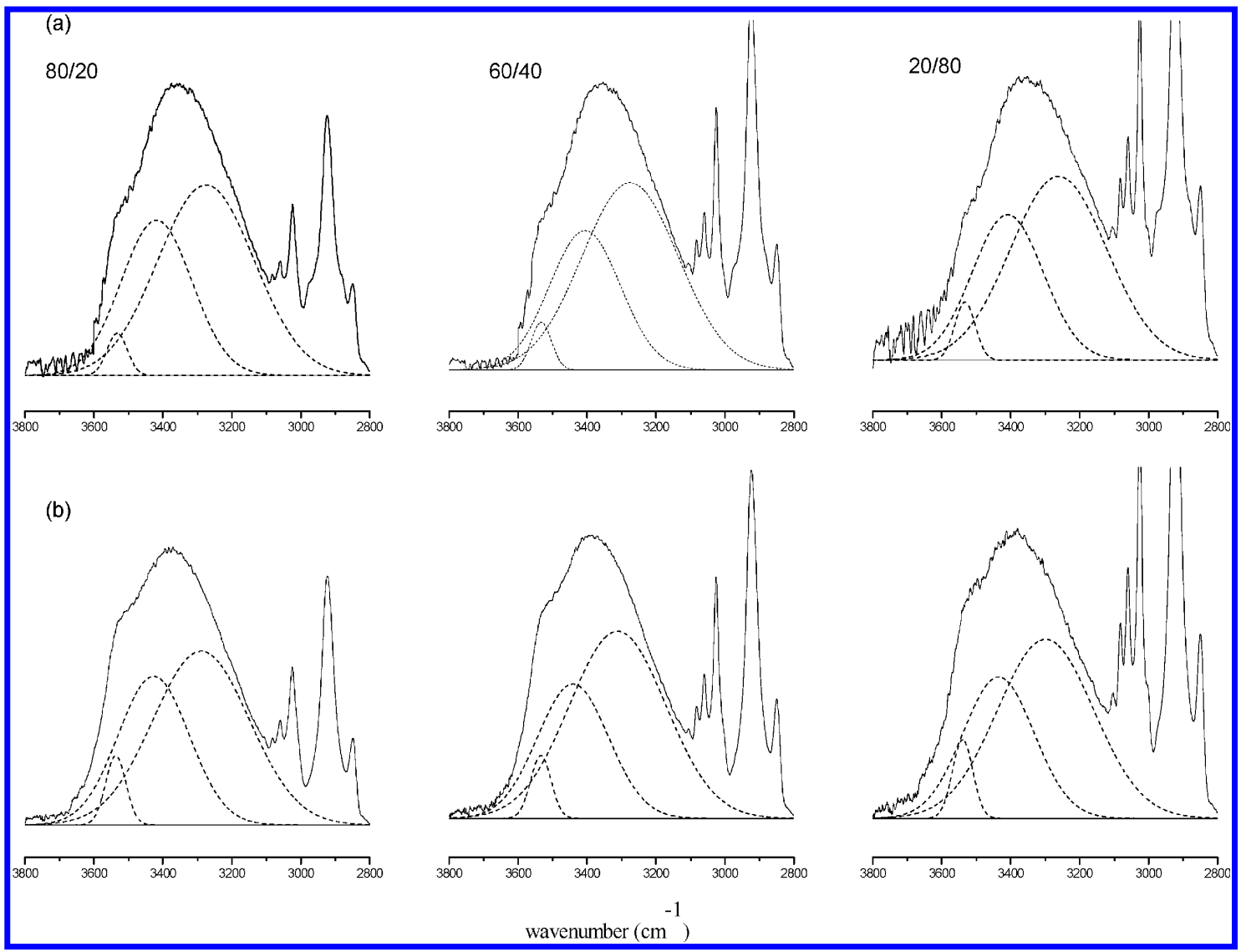

Figure 5. FTIR spectra and curve-fitting result of $\mathrm{PVPh} / \mathrm{PS}$ blends (a) at room temperature and (b) after the $180{ }^{\circ} \mathrm{C}$ thermal treatment procedure.

PS blends before and after the thermal treatment. The fractions of free and inter- and intramolecularly hydrogen-bonded by- droxyl bands do not show a significant change before and after thermal treatment in the block copolymer, which is similar to 


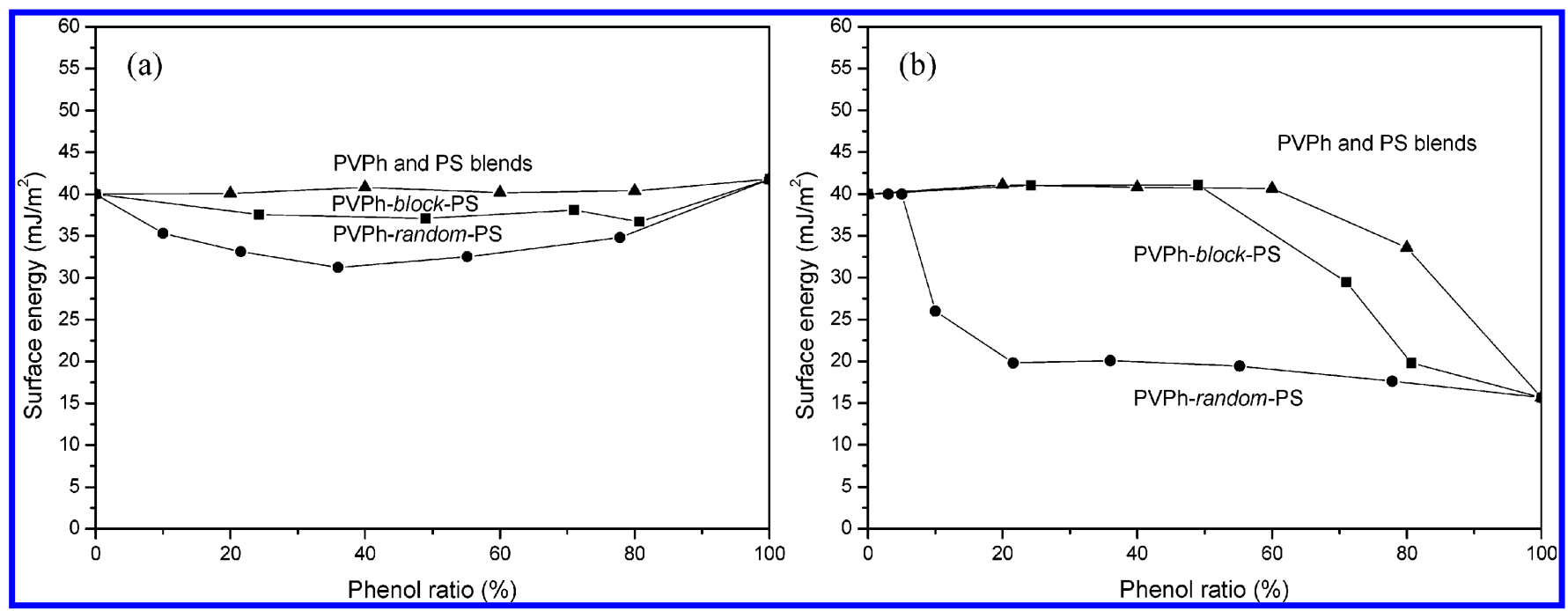

Figure 6. Surface energy of PVPh/PS random and block copolymers and their blends (a) before (b) after the thermal treatment process.

the blend system in surface energy. On the contrary, the fraction of the free hydroxyl absorption $\left(3525 \mathrm{~cm}^{-1}\right)$ increases significantly. The peak position of the intermolecular hydroxyl band shifts to higher wavenumber, and its peak area decreases in pure $\mathrm{PVPh}$ and PVPh-r-PS copolymers after thermal treatment, implying a decrease of the intermolecular hydrogen-bonding fraction. The styrene moiety can act as an "inert" (non-hydrogenbonding) diluent to space the vinylphenol segment. In our previous work, ${ }^{18}$ we have studied the effect of an inert diluent segment on the miscibility behavior of PVPh- $r$-PS copolymers and found that the incorporation of a styrene moiety into the $\mathrm{PVPh}$ polymer chain can dilute and decrease the strong selfassociation in the PVPh component. The spacing of these vinylphenol groups tends to decrease the average hydroxylhydroxyl distance and increase the fraction of free hydroxyl in $\mathrm{PVPh} / \mathrm{PS}$ random copolymers and provides a positive effect to lower the surface energy of the polymer. On the other hand, the interference of the styrene segment tends to prevent the vinylphenol segment from migrating to the surface, which can be regarded as a negative effect, i.e., an increase in the surface energy of the material.

Previous studies ${ }^{25,26}$ suggested that the surface energy of a random copolymer usually follows the linear relation $\gamma=x_{1} \gamma_{1}$ $+x_{2} \gamma_{2}$. This behavior was observed by Rastogi et al. ${ }^{27}$ in random copolymers of ethylene oxide and propylene oxide. It is well-known that backbone lengths of each component have to be taken into account when dealing with copolymers. A greater length in block copolymers or polymer blends is more favorable to induce micro- or macrophase separation and enhances migration of the lower surface free energy component to the surface. When the backbone length of the block is decreased and randomly distributed, as in random copolymers, the preferential accumulation of the low-energy segments at the surface decreases due to conformational restrictions of the polymer chains.

It is interesting to note that, before and after thermal treatment, the above relationship between sequential distribution and surface energy does not exist in the $\mathrm{PVPh} / \mathrm{PS}$ copolymer system. Figure 6 summarizes the surface energies of $\mathrm{PVPh} / \mathrm{PS}$ random and block copolymers and blends before and after thermal treatment. After thermal treatment, the surface energies of the random copolymers decrease to $19.8 \mathrm{~mJ} / \mathrm{m}^{2}$; even the $\mathrm{PVPh}$ content is only $22 \mathrm{~mol} \%$. The surface energy of block copolymers starts to decrease at a relatively higher PVPh content ( $>50 \mathrm{~mol} \%$ ), while the surface energies of blends do not change significantly over the whole composition range. For both block copolymers and blends, the intermolecular hydrogen-bonding fractions do not decrease by incorporation of an inert diluent component (polystyrene) because of phase separation, on the basis of DSC results. In addition, the aggregation of the homopolymer segment tends to prevent the vinylphenol segment from migrating to the surface. XPS results (Table 2) show that the atomic fraction of oxygen, an indication of the vinylphenol segment content on the surface, increases drastically after thermal treatment, except for the $\mathrm{PVPh} / \mathrm{PS}$ blend, which is in good agreement with the measured surface energy in this system. As a result, the combination of infrared spectra, contact angle measurements, and XPS results indicates that the decrease of intermolecular hydrogen-bonding interaction or increase of the fraction of free hydroxyl groups tends to lower the surface free energy of the polymer.

\section{Conclusions}

The decrease of the intermolecular hydrogen-bonding fraction between hydroxyl groups of $\mathrm{PVPh}$ through a simple thermal treatment procedure tends to decrease the surface energy. The lowest surface energy after thermal treatment for the pure $\mathrm{PVPh}$ is $15.7 \mathrm{~mJ} / \mathrm{m}^{2}$, even lower than that of PTFE $\left(22.0 \mathrm{~mJ} / \mathrm{m}^{2}\right)$. The sequence distribution of the vinylphenol group in $\mathrm{PVPh}-\mathrm{co}$-PS copolymers plays an important role in dictating the final surface energy after thermal treatment. This finding provides a possibility to prepare a new class of low-surface-energy materials through simple thermal treatment by decreasing the intermolecular interaction of polymers.

Acknowledgment. This research was supported financially by the National Science Council, Taiwan, Republic of China, under Contract No. NSC-95-2221-E-009-166-MY3 and Ministry of Education "Aim for the Top University" (MOEATU) program.

\section{References and Notes}

(1) Li, H.; Wang, X.; Song, Y.; Liu, Y.; Li, Q.; Jiang, L.; Zhu, D. Angew. Chem. Int., Ed. 2001, 40, 1743.

(2) Aussillous, P.; Quere, D. Nature 2001, 411, 924.

(3) Shirtcliffe, N. J.; McHale, G.; Newton, M. I.; Perry, C. C. Langmuir 2005, $21,937$.

(4) Wang, S.; Feng, L.; Liu, H.; Sun, T.; Zhang, X.; Jiang, L.; Zhu, D. ChemPhysChem 2005, 6, 1475.

(5) Coulson, S. R.; Woodward, I.; Badyal, J. P. S.; Brewer, S. A.; Willis, C. J. Phys. Chem. B 2000, 104, 8836. 
(6) Jin, M.; Feng, X.; Xi, J.; Zhai, J.; Cho, K.; Feng, L.; Jiang, L. Macromol. Rapid Commun. 2005, 26, 1805.

(7) Feng, L.; Zhang, Z.; Mai, Z.; Ma, Y.; Liu, B.; Jiang, L.; Zhu, D. Angew. Chem., Int. Ed. 2004, 43, 2012.

(8) Hillborg, H.; Tomczak, N.; Olah, A.; Schonherr, H.; Vancso, G. J. Langmuir 2004, 20, 785.

(9) $\mathrm{Wu}, \mathrm{S}$. Polymer Interface and Adhesion; Marcel Dekker: New York, 1982.

(10) Feiring, A. E.; Imbalzano, J. F.; Kerbow, D. L. Adv. Fluoroplast. Plast. Eng. 1994, 27.

(11) Carlson, D. P.; Schmiegel, W. Ullmann's Encyclopedia of Industrial Chemistry; VCH Verlagsgesellschaft: Weinheim, Germany, 1988; p 393.

(12) Wang, C. F.; Su, Y. C.; Kuo, S. W.; Huang, C. F.; Sheen, Y. C.; Chang, F. C. Angew. Chem., Int. Ed. 2006, 45, 2248.

(13) Kobayashi, H.; Owen, M. J. Trends Polym. Sci. 1995, 3, 5.

(14) Schmidt, D. L.; Coburn, C. E.; DeKoven, B. M.; Potter, G. E.; Meyers, G. F.; Fischer, D. A. Nature 1994, 368, 41.

(15) Owen, M. J. Comments Inorg. Chem. 1988, 7, 195

(16) Ma, K. X.; Chung, T. S. J. Phys. Chem. B 2001, 105, 4145.

(17) Tsibouklis, J.; Graham, P.; Eaton, P. J.; Smith, J. R.; Nevell, T, G.; Smart, J. D.; Ewen, R. J. Macromolecules 2000, 33, 8460.
(18) Kuo, S. W.; Chang, F. C. J. Polym. Sci., Part B: Polym. Phys. 2002, 40, 1661 .

(19) Tung, P. H.; Huang, C. F.; Chen, S. C.; Hsu, C. H.; Chang, F. C. Desalination 2006, 200, 55.

(20) Fowkes, F. W. In Adhesion and Adsorption of Polymers, Polymer Science and Technology; Lee, L. H., Ed.; Plenum Press: New York, 1980; Vol. 12A, p 43.

(21) Drelich, J.; Miller, J. D.; Good, R. J. J. Colloid Interface Sci. 1996, 179,37

(22) Good, R. J.; van Oss, C. J. In Modern Approaches to Wettability: Theory and Applications; Schrader, M. E., Loeb, G., Eds.; Plenum Press: New York, 1992; pp 1-27.

(23) Yoshimasa, U.; Takashi, N. Langmuir 2005, 21, 2614.

(24) Yuan, F.; Wang, W.; Yang, M.; Zhang, X.; Li, J.; Li, H.; He, B. Minch, B.; Lieser, G.; Wegner, G. Macromolecules 2006, 39, 3982.

(25) Helfand, M. A.; Mazzanti, J. B.; Foue, M.; Reamey, R. H. Langmuir 1996, 12,1269 .

(26) Teraya, T.; Takahara, A.; Kajiyama, T. Polymer 1990, 31, 1149.

(27) Rastogi, A. K.; St. Pierre, L. E. J. Colloid Interface Sci. 1969, 31, 168 